\title{
Protective effects of some antioxidants against long-term intake of aspartame toxicity on liver and kidney: biochemical and histopathological approach in rats
}

\author{
Sary Kh. Abdel-ghaffar ${ }^{2}$, Mohamed Araf Adly' ${ }^{1}$, Mohamed F. El-Sayed ${ }^{1 *}$ (i) and Walaa Magdy Abd-Elsamei ${ }^{1}$
}

\begin{abstract}
Background: Aspartame is used to treat obesity, and the diabetic people could induce changes in liver and kidney structures and function. Garlic extract, melatonin and thymoquinone have an important role against aspartame toxicity due to their antioxidant properties. The current study was designed to examine the protective effects of garlic, melatonin and thymoquinone against aspartame-induced hepatorenal toxicity in albino rates.

Results: The results indicated that aspartame induced changes in the serum levels of liver parameters function (glucose, ALT, AST and ALP) and renal parameters function (urea and creatinine). Garlic, melatonin and thymoquinone reversed the values of liver and kidney enzymes levels near to or similar to that of control. The histopathological effects of aspartame on the histological structures of liver and kidney were either reduced or removed by garlic, melatonin and thymoquinone.
\end{abstract}

Conclusion: Long-term (6 months) administration of aspartame induced toxic effects on hepatorenal function and structure, whereas garlic, melatonin and thymoquinone resulted in hepatorenal ameliorative and protective effects.

Keywords: Aspartame, Long term, Liver function parameters, Kidney function parameters, Albino rats

\section{Background}

Aspartame is a dipeptide artificial sweetener which is widely used as a non-nutritive sweetener in various food products (Rencuzogullari et al., 2004). Aspartame is metabolized in the gastrointestinal tract into aspartic acid, phenylalanine and methanol and subsequently oxidized into formaldehyde and formic acid in many tissues. Formic acid can be considered as the principal metabolic product which is responsible for the intoxication by methanol in humans and animals (Soffiriti et al., 2006). The metabolism of aspartame was found to a large extent to be in the liver. It was found that the by-products of

\footnotetext{
*Correspondence: m_farag6000@yahoo.com

'Zoology Department, Faculty of Science, Sohag University, Sohag, Egypt Full list of author information is available at the end of the article
}

such metabolism caused a hepatic damage by producing oxygen containing molecules that damage structure and function of cell components through oxidation (Fernandez-Checa et al., 1997). Oral administration of aspartame for long term (6 months) caused a significant increase in the activities of alanine aminotransferase (ALT), aspartate aminotransferase (AST) and alkaline phosphatase (ALP). Also, administration of aspartame at a dose of $1000 \mathrm{mg} / \mathrm{kg}$ body wt. caused pathological changes in the liver of male Wistar rats indicated by leukocyte infiltration (Abhilash et al., 2011). Histologically, oral administration of aspartame at a dose of $250 \mathrm{mg} / \mathrm{kg}$ body wt. daily for two months resulted in irregular nuclei and vacuolated cytoplasm with ill-defined cell boundaries in the liver of male albino rats (El Haliem \& Mohamed, 2011). Aspartame supplementation at a dose of $40 \mathrm{mg} /$ 
kg body wt. for six weeks caused a significant elevation in the activities of ALT and AST in male Wistar albino rats (Prokic et al., 2015). Administration of aspartame at a dose of 15,35 and $70 \mathrm{mg} / \mathrm{kg}$ body wt. for nine weeks resulted in a significant increase in the levels of ALT and AST at 35 and $70 \mathrm{mg} / \mathrm{kg}$ body wt.. Also, aspartame at a dose of 35 and $70 \mathrm{mg} / \mathrm{kg}$ body wt. caused severe necrosis, periportal infiltration, congestion and dilatation of sinusoids of the hepatocytes of male Wistar rats (Adaramoye \& Akanni, 2016). It was reported that administration of $240 \mathrm{mg} / \mathrm{kg}$ body wt./day of aspartame for two months resulted in a significant increase in AST level and a significant decrease in ALP level, while no change was observed in the level of ALT. Also, aspartame resulted in a significant increase in the serum glucose and triglycerides levels, whereas non-significant changes in the serum level of cholesterol were observed. Degeneration of hepatocytes was indicated by swollen cells, intense inflammatory cells aggregation in the portal area, congestion of portal vein with focal hepatic necrosis and infiltration of inflammatory cells in the liver of the male Wistar albino rats on administration of $240 \mathrm{mg} / \mathrm{kg}$ body weight of aspartame (Lebda et al., 2017).

Oral administration of aspartame at a dose of $250 \mathrm{mg} /$ $\mathrm{kg}$ body wt./day for six weeks to male albino rats resulted in an increase in the serum levels of ALT, AST and ALP, whereas it did not cause a change in the serum glucose level. Liver sections of aspartame-treated rats showed congestion in the central veins and sinusoids, as well as periductal fibrosis surrounding bile ducts (Abd El Wahab et al., 2017). The liver section of aspartame-treated albino rats at a dose of $40 \mathrm{mg} / \mathrm{kg} /$ body wt./day for six weeks caused a damage in the hepatocytes indicated by cytoplasmic vacuoles of variable size in the cytoplasm, pyknosis and fragmentation of the nuclei; congestion in the central veins and inflammation in the parenchyma (Maaruf et al., 2017). Moreover, administration of aspartame orally at dose of 50 and $150 \mathrm{mg} / \mathrm{kg}$ body wt. daily for six months resulted in a significant increase in the serum levels of ALT and AST, and degeneration, necrosis of hepatocytes, filling of cytoplasm with numerous vacuoles, hyperchromatism, pyknosis and fragmentation of the nuclei in the liver of female albino rats were observed (Moubarz et al., 2018).

It is well known that kidney is the organ which plays an important role in the excretion of the various waste metabolite products, so studies have increased to evaluate the toxic effect of aspartame on the structure and function of the kidney (Moubarz et al., 2018; Martins \& Azoubel, 2007). It was found that oral administration of aspartame at a dose of $0.25 \mathrm{gm} / \mathrm{L}$ for 60 days in male Wistar albino rats resulted in a significant elevation in the serum urea and creatinine levels (Bahr \& Zaki, 2014).
Similar results were also reported in male Wistar albino rats which was fed with $40 \mathrm{mg} / \mathrm{kg}$ body wt. of aspartame for 30 and 90 days which showed a significant increase in urea and creatinine levels, while uric acid level was significantly decreased (Choudhary \& Devi, 2014). Also, oral administration of aspartame at a dose of 35 and $70 \mathrm{mg} / \mathrm{kg}$ body wt. for 9 weeks in male Wistar albino rats caused a significant increase in the serum levels of urea and creatinine (Adaramoye \& Akkani, 2016). Moreover, treatment of male albino rats with $250 \mathrm{mg} / \mathrm{kg}$ body wt. of aspartame for six weeks caused a significant increase in serum urea and creatinine levels (Abd El Wahab et al., 2017). Oral administration of male Wistar albino rats with 75 and $150 \mathrm{mg} / \mathrm{kg}$ body wt. of aspartame for 30 days caused a significant elevation in the serum uric acid, urea and creatinine levels (Al-Eisa et al., 2018). In contrast to the above-mentioned results, it was reported that oral administration of aspartame at a dose of 50,500 and $1000 \mathrm{mg} / \mathrm{kg}$ body wt. for six months in male Wistar rats did not show any change in the levels of creatinine, urea and uric acid from those of the control animals (Abhilash et al., 2011). Histologically, it was reported that oral administration of aspartame at low and high doses for short- and long-term caused significant structural changes indicated by convoluted tubular epithelium, pyknotic nuclei of the renal tubules, vacuolated cytoplasm and atrophic glomeruli (El Haliem \& Mohamed, 2011); severe congestion of vessels in the cortex and medulla (Adaramoye \& Akanni, 2016); congestion in the sclerotic blood vessels with swelling in the lining epithelial cells of the renal tubules (Hozayen et al., 2014); degeneration of renal capsules, proximal tubules, distal tubules and congested cortical blood vessels (Abd El Wahab et al., 2017); and hydropic degeneration of renal tubular epithelial cells, interstitial cells infiltration, congested vacuolar space with enlarged glomeruli and aggregation of inflammatory cells between renal tubules (Al-Eisa et al., 2018).

Garlic (Allium sativum) has been used as a traditional food and in the medical field since ancient times. The medical effects of garlic are mainly due to the organosulfur compounds present in it (Banerjee et al., 2001; Shirzad et al., 2011). Garlic plays an important role in preventing lipid peroxidation by reactive oxygen species, and oxidative stress induced damage in the biological system (Mikaili et al., 2013; Nasr \& Saleh, 2014). Treatment of rats with garlic had a potential protective effect at low doses on the morphology of liver and kidney (Banerjee et al., 2001) and prevented free radicals generation in these organs (Rietz et al., 1995). It was demonstrated that garlic has antioxidant and protective effects against toxic substances induced pathological changes in the structure of rat liver and kidney (Nasr, 2014; Sajitha et al., 2016). 
Melatonin which is secreted by pineal gland during night (Gamez-Moreno et al., 2010) is a hormone which acts as a strong antioxidant and anti-inflammatory agent (Ambaldage et al., 2016). It protects liver and kidney from oxidative stress induced by toxic elements (Amin et al., 2015; Kireev et al., 2013). It was found that melatonin has a protective effect against the toxicity of heavy metals which induced pathological changes in structure and function of rat liver and kidney (El-Sayed et al., 2019).

Thymoquinone which is the main constituent of the volatile oil isolated from Nigella sativa acts as antioxidant preventing free radicals generation produced by the toxic treatments in the biological system (Hossienzdeh et al., 2007). It was reported that thymoquinone had a protective effect against toxic metals and chemicals induced oxidative stress in the liver and kidney of rat (Badary et al., 2003; El-Sayed et al., 2019; Nagi et al., 1999). Since very studies were carried out on the protective effect of garlic, melatonin and thymoquinone against the toxicity of long-term intake of aspartame on the hepatorenal function and structure. So, the present study was designed to evaluate the protective effects of garlic, melatonin and thymoquinone against aspartame toxicity for six months on the hepatorenal function and structure in albino rats (Figs. 1, 2).

\section{Methods \\ Chemicals}

Chemicals used in this study were of analytical grade supplied by Loba Chemie (India): aspartame (L-aspartyl-L-phenylalanine methyl ester), garlic, melatonin ( $\mathrm{N}$-acetyl-5-methoxytryplamine) and thymoquinone ( $N$-isopropyl-5-methyl-1,4-benzoquinone).

\section{Animals}

Eighty-four (42 male and 42 female) albino rats (Rattus rattus) weigh approximately 160-180 gm (8-10 weeks aged). The animals were obtained from the animal house, Faculty of Medicine, Assuit University. The animals were housed in stainless steel cages, six per each cage at room temperature and acclimated to laboratory conditions two weeks before experimentation, with 12-h light and 12-h dark exposure. They were allowed to have food and water ad libitum (standard rat food pellets).

\section{Experimental design}

After an acclimated period (two weeks), the rats of each gender were divided into seven groups and were administrated the treatments orally for six months as follows:-

Group I: was kept as normal control and received drinking water and food.

Group II: was given aspartame in dist. water at a dose of $40 \mathrm{mg} / \mathrm{kg}$ body wt./day (CFR, 2005).
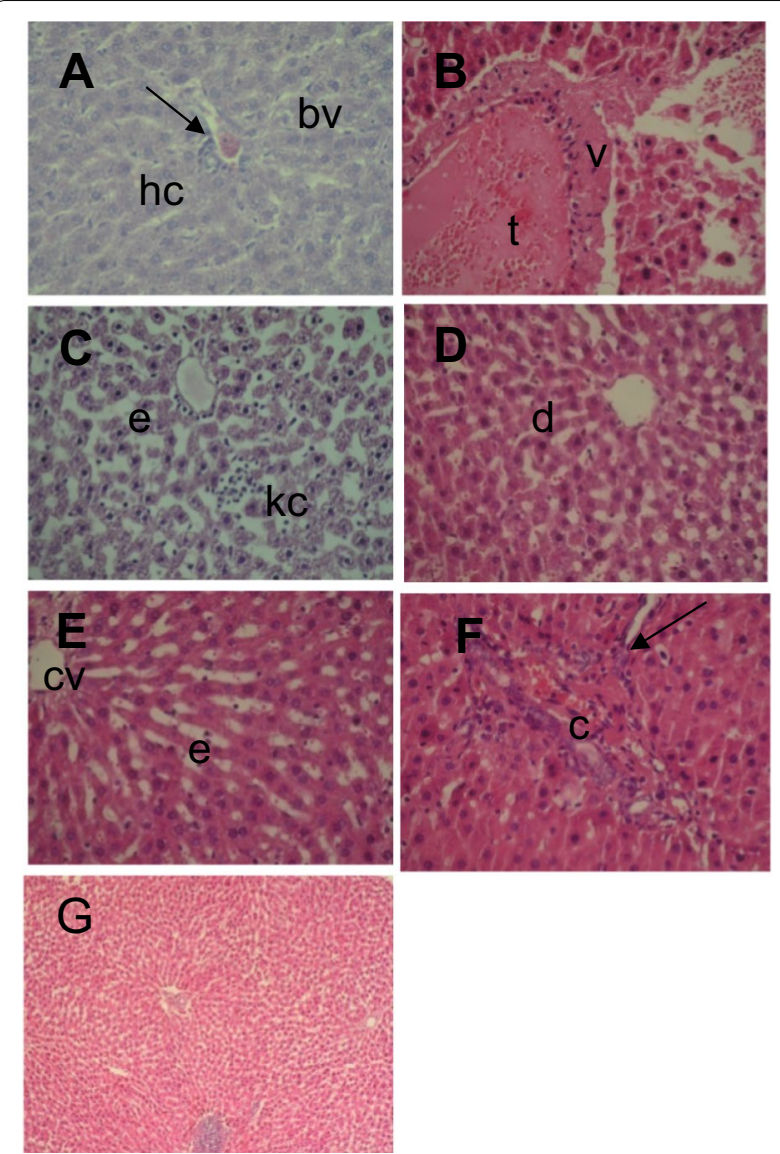

Fig. 1 Photomicrographs of liver section from male and female rats, respectively, of $\mathbf{A}$ control groups showing normal hepatocytes arranged in hepatic cords (hc) with the presence of blood vessel (bv) and bile canal (arrow) in portal area $(\times 10 \times 40)$; B rats from groups treated with aspartame showing vasculitis $(v)$ in hepatic blood vessels with the presence of mixed thrombus and degeneration ( $t$ ) of endothelial cell lining blood vessel $(\times 10 \times 40)$; $C$ rats from groups treated with aspartame showing hepatic edema (e) with dilatation of Disse spaces and activation of Kupffer cells $(\mathrm{kc})(\times 10 \times 40)$; D rats from groups treated with aspartame and garlic showing hepatocellular degeneration (d) $(\times 10 \times 40) ; \quad \mathbf{E}$ rats from group treated with aspartame and melatonin showing hepatic edema (e) with dilatation of central vein (cv) and Disse space $(\times 10 \times 40) ; \quad F$ rats from groups treated with aspartame and thymoquinone showing congestion (c)in the portal area with inflammatory cell reaction (arrow) $(\times 10 \times 40)$; and $\mathbf{G}$ rats from groups treated with aspartame and melatonin plus thymoquinone showing more or less normal hepatic structure $(\times 10 \times 10)$
Group III: was given garlic in dist. water at a dose of $50 \mathrm{mg} / \mathrm{kg} /$ body wt./day (Shahdi-Pashaki et al., 2018).

Group IV: was given aspartame plus garlic as above.

Group V: was given aspartame as above plus melatonin in dist. water at a dose of $10 \mathrm{mg} / \mathrm{kg}$ body wt./day (Othmen et al., 2004). 

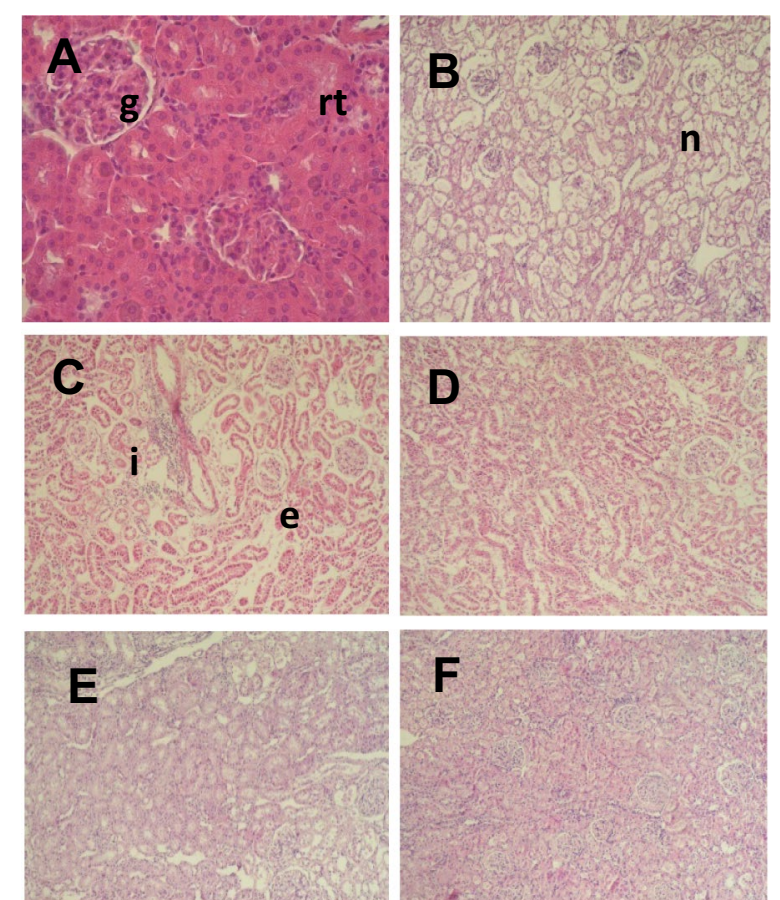

Fig. 2 Photomicrographs of kidney section from male and female rats, respectively, of $\mathbf{A}$ control male rat and $\mathbf{B}$ control rat showing normal renal tubules (rt) and glomeruli (g); $\mathbf{B}$ rats from groups treated with aspartame showing degeneration (d) of the glomerular tuft with necrosis ( $n$ ) of the renal tubular epithelial cells; $\boldsymbol{C}$ rats from groups treated with aspartame and garlic showing interstitial edema (e) in both cortex and medulla with perivascular inflammatory (i) cell reactions; $\mathbf{D}$ rats from groups treated with aspartame and melatonin showing more or less normal tubular and glomerular structure with mild interstitial edema (e); $\mathbf{E}$ rats from groups treated with aspartame and thymoquinone showing more or less normal tubular and glomerular structure; and $\mathbf{F}$ rats from groups treated with aspartame and melatonin plus thymoquinone showing normal histological structure of renal glomeruli and tubules in the renal cortex (H\&E) $(\times 10 \times 10)$

Group VI: was given aspartame as above plus thymoquinone in dist. water at a dose of $10 \mathrm{mg} / \mathrm{kg}$ body wt./ day (Danaei \& Karami, 2017).

Group VII: was given aspartame plus melatonin and thymoquinone as above.

All groups were received the treatments morning, except melatonin was given between 9.00 and $10.00 \mathrm{pm}$.

At the end of study (6 months), no changes in the health of the animals were appeared. The rats were deprived of food overnight and then were anesthetized with light diethyl ether and scarified by decapitation, and their blood was collected by cardiac puncture into EDTA sterilized sample tubes. Blood was used immediately for preparing serum to analyze liver biomarkers; glucose (Hyvarinen \& Nikkila, 1962), albumin (Doumas
\& Bigg, 1976), total proteins (Henry, 1964), alkaline phosphatase (ALP) (Prinxcipato et al., 1985), aspartate transaminase (AST) (Reitman \& Frankle, 1957), ALT (Reitman \& Frankle, 1957) and kidney biomarkers; urea (Patton \& Crush, 1977) and creatinine (Henry et al., 1974) using commercial kits (Diagnostic, Cairo, Egypt), and the activities of liver and kidney biomarkers were determined using spectrophotometer (UV 2300), Germany.

Liver and kidney samples were collected and washed in saline solution. Samples were fixed in 10\% neutral buffer formalin solution, routinely processed and embedded in paraffin. Blocks were cut at 6-8uM thick, and paraffin section was mounted on glass slides and stained with hematoxylin and eosin (H\&E) and examined by light microscope.

\section{Statistical analysis}

All values were expressed as mean $\pm \mathrm{SE}$. One-way ANOVA (SPSS, version 22, 2013) was applied to test for significance of biochemical data of different groups. Significance is set at $p<0.05$, where is $p>0.05$ was considered non statistically significant, $p<0.01$ was considered highly significant, while $p>0.0001$ was considered very highly significant in all analysis.

\section{Results}

\section{Biochemical findings}

\section{Liver biomarkers}

The serum levels of glucose, albumin and total proteins in male rats exhibited a very highly significant $(P<0.0001)$, highly significant $(P<0.01)$ and very highly significant $(P<0.004)$ increase in aspartame-treated rats relative to that of control, respectively. In female rates, the serum levels of glucose, albumin and total proteins exhibited a very highly significant $(P<0.002)$ very highly significant $(P<0.004)$ and very highly significant $(P<0.001)$ increase in aspartame-treated rats relative to that of control, respectively (Tables 1,2 ). The serum activities of ALP and ALT showed a highly significant $(P<0.01)$ elevation in aspartame-treated group of both male and female rats (Tables 1, 2) in comparison with control. Although nonsignificant increase in the activity of AST level in male rat was observed (Table 1 ), there was a highly significant $(P<0.04)$ increase in the activity of the same enzyme in female rat treated with aspartame, compared with that of the control (Table 2).

\section{Kidney biomarkers}

The serum levels of urea and creatinine exhibited a very highly significant $(P<0.0002 ; P<0.006)$ increase in male and $(P<0.006 ; P<0.0005)$ in female in 
Table 1 The impact of different treatments on the blood and hepatic parameters in male rats

\begin{tabular}{|c|c|c|c|c|c|c|c|}
\hline Parameter & Control & Aspartame & Garlic & Asp. + Garlic & Asp. + Mela & Asp. + Thym & Asp. + Mela. + thym \\
\hline Glucose (mg/dl) & $130.7 \pm 2.8$ & $137 \pm 3.46^{*}$ & $130 \pm 1.79^{\# \dagger}$ & $136.2 \pm 3.4^{* \#}$ & $135.8 \pm 8.06^{\# \#}$ & $133 \pm 2.7^{* \dagger}$ & $130.2 \pm 0.75^{\# \dagger}$ \\
\hline Albumin (mg/dl) & $2.5 \pm 0.27$ & $3.43 \pm 0.25^{*}$ & $2.46 \pm 0.24^{\#+}$ & $3.16 \pm 0.26^{* \#}$ & $3.17 \pm 0.196^{* \#}$ & $2.4 \pm 0.3^{\#+}$ & $2.6 \pm 0.34^{\# \#}$ \\
\hline Total proteins (g/dl) & $5.03 \pm 0.26$ & $5.6 \pm 0.37^{*}$ & $4.88 \pm 0.37^{\# \dagger}$ & $5.18 \pm 0.325^{\# \#}$ & $5.02 \pm 0.66^{\# \#}$ & $4.9 \pm 0.4^{\# \dagger}$ & $5.46 \pm 0.24^{* \dagger}$ \\
\hline $\operatorname{ALP}(\mathrm{U} / \mathrm{L})$ & $147.5 \pm 11.3$ & $161.7 \pm 7.5^{*}$ & $153.8 \pm 3.19^{\# \dagger}$ & $143.3 \pm 8.16^{\# \#}$ & $146.3 \pm 8.28^{\# \dagger}$ & $141 \pm 6.93^{\# \dagger}$ & $140.8 \pm 6.65^{\# \dagger}$ \\
\hline $\begin{array}{l}\text { AST } \\
(\mathrm{U} / \mathrm{L})\end{array}$ & $182.5 \pm 11.3$ & $192.5 \pm 6.66^{\#}$ & $185.16 \pm 5.49^{\#+}$ & $180.8 \pm 11.58^{\# \#}$ & $185.3 \pm 6.03^{\#+}$ & $179.2 \pm 8.6^{\# \#}$ & $180.67 \pm 10.9^{\# \#}$ \\
\hline $\operatorname{ALT}(U / L)$ & $19.83 \pm 1.29$ & $32.17 \pm 1.86^{*}$ & $20.17 \pm 1.13^{\# \dagger}$ & $27.17 \pm 4.96^{*^{\dagger}}$ & $21.17 \pm 1.47^{\#+}$ & $19.9 \pm 1.32^{\#+}$ & $26.17 \pm 3.49^{*{ }^{\dagger}}$ \\
\hline
\end{tabular}

The number of rats in each series was 6

\# $P>0.05$ (Non-significant)

${ }^{*} P>0.05$ (Significant difference with respect to control group)

${ }^{+} P>0.05$ (Significant difference with respect to aspartame-treated group)

Table 2 The impact of different treatments on the blood and hepatic parameters in female rats

\begin{tabular}{|c|c|c|c|c|c|c|c|}
\hline Parameter & Control & Aspartame & Garlic & Asp. + Garlic & Asp. + Mela & Asp. + Thym & Asp. + Mela. + thym \\
\hline Glucose (mg/dl) & $122.5 \pm 9.31$ & $132.17 \pm 4.79^{*}$ & $119.3 \pm 5.75^{\# \dagger}$ & $135.8 \pm 9.49^{* \#}$ & $148.17 \pm 12.06^{* \#}$ & $134.8 \pm 6.65^{* \#}$ & $133.7 \pm 3.88^{* \#}$ \\
\hline Albumin (mg/dl) & $2.77 \pm 0.4$ & $3.47 \pm 0.24^{*}$ & $2.78 \pm 0.39^{\#+}$ & $3.08 \pm 0.22^{\# \#}$ & $3.2 \pm 0.21^{\# \dagger}$ & $2.58 \pm 0.12^{\# \dagger}$ & $2.65 \pm 0.21^{\# \dagger}$ \\
\hline Total proteins (g/dl) & $5.1 \pm 0.41$ & $6.28 \pm 0.09^{*}$ & $5.2 \pm 0.58^{\#+}$ & $5.17 \pm 0.53^{\# \dagger}$ & $5.33 \pm 0.71^{\# \dagger}$ & $4.95 \pm 0.57^{\#+}$ & $5.6 \pm 0.23^{*+}$ \\
\hline $\operatorname{ALP}(\mathrm{U} / \mathrm{L})$ & $107.8 \pm 14.68$ & $148.7 \pm 17.8^{*}$ & $111.2 \pm 12.6^{\#+}$ & $121.3 \pm 17.5^{\# \#}$ & $109.8 \pm 12.3^{\#+}$ & $108 \pm 6.84^{\#+}$ & $112.7 \pm 7.3^{\# \dagger}$ \\
\hline AST (U/L) & $98.8 \pm 4.26$ & $104.17 \pm 4.4^{*}$ & $97.5 \pm 6.09^{\#+}$ & $102 \pm 7.07^{\# \#}$ & $98.7 \pm 4.55^{\# \#}$ & $100.3 \pm 3.08^{\# \#}$ & $101.2 \pm 7.4^{\# \#}$ \\
\hline ALT (U/L) & $23.17 \pm 2.3$ & $28 \pm 1.67^{*}$ & $23.17 \pm 1.94^{\#+}$ & $27 \pm 6.93^{\# \#}$ & $23.67 \pm 3.14^{\#+}$ & $26.33 \pm 2.06^{* \#}$ & $23.17 \pm 2.32^{* \#}$ \\
\hline
\end{tabular}

The number of rats in each series was 6

\# $P>0.05$ (Non-significant)

${ }^{*} P>0.05$ (Significant difference with respect to control group)

${ }^{+} P>0.05$ (Significant difference with respect to aspartame-treated group)

Table 3 The impact of different treatments on the blood and kidney parameters in male rats

\begin{tabular}{lccccccc}
\hline Parameter & Control & Aspartame & Garlic & Asp. + Garlic & Asp. + Mela & Asp. + Thym & Asp. + Mela. + thym \\
\hline Urea $(\mathrm{mg} / \mathrm{dl})$ & $26.12 \pm 1.58$ & $32.3 \pm 1.38^{*}$ & $26.02 \pm 2.1^{\# \dagger}$ & $26.8 \pm 1.37^{\# \dagger}$ & $25.5 \pm 5.25^{\# \dagger}$ & $27.38 \pm 2.42^{\#+}$ & $26.7 \pm 2.62^{\# \dagger}$ \\
Creatinine $(\mathrm{mg} / \mathrm{dl})$ & $0.35 \pm 0.055$ & $0.55 \pm 0.01^{*}$ & $0.35 \pm 0.054^{\# \#}$ & $0.48 \pm 0.17^{\# \#}$ & $0.33 \pm 0.15^{\# \dagger}$ & $0.33 \pm 0.12^{\# \dagger}$ & $0.38 \pm 0.04^{\# \dagger}$ \\
\hline
\end{tabular}

The number of rats in each series was 6

\# $P>0.05$ (Non-significant)

* $P>0.05$ (Significant difference with respect to control group)

${ }^{\dagger} P>0.05$ (Significant difference with respect to aspartame-treated group)

Table 4 The impact of different treatments on the blood and kidney parameters in female rats

\begin{tabular}{lccccccc}
\hline Parameter & Control & Aspartame & Garlic & Asp. + Garlic & Asp. + Mela & Asp. + Thym & Asp. + Mela. + thym \\
\hline Urea $(\mathrm{mg} / \mathrm{dl})$ & $26.5 \pm 2.4$ & $30.12 \pm 1.24^{*}$ & $26.3 \pm 2.66^{\#+}$ & $27.2 \pm 2.01^{\# \dagger}$ & $24.5 \pm 0.93^{\# \dagger}$ & $27.2 \pm 1.93^{\#+}$ & $27.3 \pm 1.51^{\#+}$ \\
Creatinine $(\mathrm{mg} / \mathrm{dl})$ & $0.58 \pm 0.07$ & $0.39 \pm 0.12^{*}$ & $0.58 \pm 0.12^{\# \dagger}$ & $0.55 \pm 0.14^{\# \dagger}$ & $0.62 \pm 0.04^{\# \dagger}$ & $0.53 \pm 0.08^{\# \dagger}$ & $0.62 \pm 0.04^{\# \dagger}$ \\
\hline
\end{tabular}

The number of rats in each series was 6

\# $P>0.05$ (Non-significant)

${ }^{*} P>0.05$ (Significant difference with respect to control group)

${ }^{+} P>0.05$ (Significant difference with respect to aspartame-treated group) 
aspartame-treated, respectively (Tables 3,4 ) compared with those of the control.

\section{Antioxidants}

Garlic, melatonin and thymoquinone and the combination of melatonin with thymoquinone (as antioxidants) either removed the toxic effect of aspartame or restored the levels of liver biomarkers in male and female rats (Tables 1, 2), and kidney biomarkers in male and female rats (Tables 3,4 ) to the levels near or similar to those of control groups compared with the aspartame-treated groups. Although there was an increase and a decrease in the levels of liver and kidney biomarkers in antioxidants-treated groups related to the aspartame-treated groups, no significant differences were found between the antioxidants-treated groups and the normal control groups (Tables 1, 2, 3, 4).

\section{Histological findings \\ Liver}

Hematoxylin and eosin liver stained sections from the control rats (Plate 1A) showed normal hepatocytes arranged in hepatic cords with the presence of central blood vessel and bile canal in the portal area.

Rats treated with aspartame showed vasculitis and degeneration of endothelial cell lining blood vessels with the presence of mixed thrombus (Plate $1 \mathrm{~B}$ ). Hepatic edema with dilation of Disse space and activation of Kupffer cells were also seen (plate 1C).

Rats treated with aspartame combined with garlic showed mild degeneration with mononuclear cell infiltration (Plate 1D).

Rats treated with aspartame and melatonin showed hepatic edema (HE) with dilatation of the central vein and Disse space (Plate1E).

Liver section from rats treated with aspartame combined with thymoquinone showed congestion of the blood vessel in the portal area with inflammatory cell reaction (Plate 1F).

Liver sections from rats treated with aspartame combined with melatonin and thymoquinone showed more or less normal hepatic structure (Plate 1G).

\section{Kidney}

Hematoxylin and eosin stained kidney sections from control rats showed normal renal medulla, renal cortex, renal tubules and renal glomeruli (Plate 2A).

Kidney section from aspartame-treated rats showed degeneration of glomerular tuft with necrosis of the renal tubular epithelium (Plate 2B).
Kidney section from aspartame combined with garlic-treated rats showed interstitial edema with perivascular inflammatory cell reaction (Plate 2C).

Kidney section from rats treated with aspartame combined with melatonin showed more or less normal glomerular structure with mild interstitial edema (Plate 2 D).

Kidney sections from rats treated with aspartame combined with thymoquinone as well as those treated with aspartame combined with both melatonin and thymoquinone showed more or less normal tubular and glomerular structures (Plate E, F).

\section{Discussion}

To our knowledge, studies concerning the ameliorative or the protective effects of garlic, melatonin and thymoquinone on the long-term intake of aspartame toxicity on the hepatorenal function and structure in the experimental animals are very limited. So, the present study was designed to highlight the protective effect of garlic, melatonin and thymoquinone on the changes induced by acceptable daily intake dose of aspartame $(40 \mathrm{mg} / \mathrm{kg} /$ day) to animals which was established by European food Safety Authority and US Food and Drug Administration (Magnuson et al., 2007), on both biochemical parameters and histological structures of the liver and kidney of male and female albino rats.

The results of the current study indicated a marked elevation in the serum levels of glucose, albumin and total proteins in aspartame-treated animals. It has been stated that the increased levels of glucose and total proteins are a useful marker for hepatic damage (Pagana \& Pagana, 2002). In agreement with our results, Prokic et al. (2015) demonstrated that aspartame caused an increase in the levels of serum glucose and total proteins. Also, the results of the current study revealed an elevation in the serum levels of ALP, AST and ALT. It was indicated that an elevation in the levels of these enzymes is an indication of hepatic cellular damage (Pagana \& Pagana, 2002). These biochemical changes were supported by the histological results in the current study which are in agreement with the previous studies on the toxicity of aspartame on the liver of albino rats (Soffiritti et al., 2007; Abd Elfatath et al., 2012). The present histological findings showed that liver sections from rats administrated with aspartame displayed vasculitis in the hepatic blood vessels with the presence of mixed thrombosis and degeneration of endothelial cell lining blood vessel in the male and hepatic edema with dilatation of Disse spaces and activation of Kupffer cells in female rats. Thus, the increase in the levels of hepatic enzymes, glucose and total proteins led to the disruption of membrane lipid bilayer structure due to the presence of reactive oxygen 
species which were produced as a result of oxidative stress leading to the release of these enzymes in detectable quantity from the cytosol to the blood stream. The reactive oxygen species may lead to the oxidation of the polyunsaturated fatty acid leading to the disruption of the lipid bilayer of the hepatic plasma membranes (Choudhary \& Devi, 2014). So the present study confirms that aspartame has a toxic effect on the hepatic function and structure by inducing oxidative stress as a result of methanol metabolites of aspartame that increase the generation of free radicals.

It has been documented that garlic, melatonin and thymoquinone act as an antioxidants preventing lipid peroxidation and stress induced by the toxic elements and chemical substances in the biological systems. They act as free radical scavengers preventing the damage in the liver and kidney function and structure against the toxicity exerted by various toxic chemicals and substances (Sajitha et al., 2016; Kirrev et al., 2013; El-Sayed et al., 2019). This seems to be the case in the present study, since administration of garlic, melatonin and thymoquinone removed the toxic effects of aspartame on the liver biomarker enzymes (serum glucose, total proteins, albumin, ALP, AST and ALT) in a way that these antioxidants restored the levels of the liver biochemical parameters to values similar or near to that of the normal control group in rats. These findings were supported by the histological findings that showed the liver sections of rats treated with melatonin combined with thymoquinone appeared histologically more or less normal. However, mild pathological changes were observed in the liver sections of rats treated with garlic and thymoquinone.

In the present study, oral administration of aspartame for 6 months affected the kidney function in rats. This effect was indicated by a significant increase in the serum urea and creatinine levels. These findings are in agreement with the study of Marielza et al., (2007) who stated that aspartame nephrotoxicity is the major side effect of aspartame.

It was stated that one of the early signs of renal dysfunction is the elevation in the serum creatinine (Nitescu et al., 2006). In accordance with the above results, aspartame induced a highly significant increase in the serum levels of urea and creatinine (Parthasathry et al., 2006). The elevated serum levels of urea and creatinine are a sign of reduced ability of the kidney to eliminate the toxic metabolic substances (Hummadi, 2012). It is known that methanol is one of the aspartame metabolites which is a toxicant caused renal dysfunction (Tsakiris et al., 2006). So, the elevated serum levels of urea and creatinine in aspartame-treated rats could be due to increased free radicals produced by methanol (metabolite of aspartame), and hence, it affects the normal functioning of the kidney in rats.

In the present study, long-term administration of aspartame induced histological changes in the kidney structure of rats. These histopathological changes are represented by degeneration of the glomerular tuft with necrosis of the renal tubular epithelial in male rats and degeneration in renal tubular epithelial cells, while the glomeruli appear more or less normal in female rats. These findings confirm the previous results (kidney biomarkers). These histopathological changes induced by aspartame, in the present study, are in accordance with the study of Ashok and Sheeladevi (2015) who stated that long-term (90) days) consumption of aspartame caused histopathological changes in the rat kidney. In agreement with the above results, Ibrahim and Hussein (2014) reported that oral administration of aspartame for 8 weeks caused histopathological changes in the kidney of rat.

The present study clearly confirms that aspartame induced oxidative damage in the rat kidney since high concentrations of serum urea and creatinine were observed. Similar results have been stated that kidney dysfunction may be due to aspartame administration occurred via oxidative stress (Bilton, 2013). In the present study, kidney dysfunction was due to toxic effect of aspartame which was confirmed by the histopathological changes induced by aspartame in the rat kidney structure. It was reported that the toxic effect of aspartame is due to the methanol and aspartic acid as by-products of aspartame metabolism (Butchko et al., 2002).

The kidney sections from rats treated with melatonin combined with aspartame showed more or less normal tubular and glomerular structure with mild interstitial edema, while those treated with thymoquinone and aspartame revealed more less normal tubular and glomerular structure. On the other hand, treating of rats with aspartame combined with melatonin plus thymoquinone resulted in normal histological structure of renal glomeruli and tubules in the renal cortex, and normal tubules in the renal medulla. However, administration of aspartame combined with garlic did not remove the toxic effects of aspartame on kidney structure, since interstitial edema in both cortex and medulla in the male rat kidney and interstitial edema with perivascular inflammatory reaction in the female rat kidney were observed. Here, we can speculated that melatonin combined with thymoquinone has the potential to offer direct cytoprotective effects in the rat kidney, even any oxidative stress exerted by aspartame than that of garlic. 


\section{Conclusions}

In conclusion, the present study indicates that longterm (6 months) administration of aspartame at a dose of $40 \mathrm{mg} / \mathrm{kg}$ body wt. caused histopathological changes in the structure of rat liver and kidney and consequently affects their functions. These pathological changes may be due to the oxidative stress induced by aspartame leading to generation of free radicals as a result of the by-product (methanol and aspartic acid) of aspartame metabolism and oxidative stress. The present study also highlights the antioxidant effects of garlic, melatonin and thymoquinone against oxidative damage of rat hepatorenal function and structure treated with aspartame. It should be noted that the differences in the histopathological changes between male and female rats were not significant. The antioxidant actions of melatonin and thymoquinone were more potent than that of garlic in restoring normal structure and function of liver and kidney in the studied animals.

\section{Abbreviations}

ALT: Alanine transaminase; AST: Aspartate transaminase; ALP: Alkaline phosphatase.

\section{Acknowledgements}

Authors would like to thank members of Pathology and Clinical Pathology Department, Assuit University, Faculty of Veterinary medicine, Assuit, Egypt, for their cooperation.

\section{Authors' contributions}

WM has done experiments and participated in writing the manuscript. MF, S $\mathrm{KH}$ and MA have participated in doing the experiments, writing and revising the manuscript and making the experimental design. All authors read and approved the final manuscript.

\section{Funding}

This study was funded in part by the Zoology Department, Faculty of Science, Sohag University, Egypt.

\section{Availability of data and materials}

Datasets generated and analyzed during the current study are available on reasonable request to the corresponding author.

\section{Declarations}

\section{Ethics approval and consent to participate}

All animals used in this study were reared and treated according to the basis of international care in an ethical way. The reference number is not applicable.

\section{Consent for publication}

Not applicable.

\section{Competing interests}

The authors declare that they have no competing interests.

\section{Author details}

'Zoology Department, Faculty of Science, Sohag University, Sohag, Egypt. ${ }^{2}$ Pathology and Clinical Pathology Department, Faculty of Veterinary Medicine, Assuit University, Assuit, Egypt.

Received: 29 June 2020 Accepted: 22 September 2021

Published online: 23 October 2021

\section{References}

Abd El-fatah, A. A., Ghaly, I. S., \& Hanafy, S. M. (2012). Cytotoxic effect of aspartame (Diet sweet) on the histological and genetic structure of female albino rats and their offspring. Pakistan Journal of Biological Sciences, 15(9), 904-918.

Abd El Wahab, A. H., Yousef, A. F., Ramadan, B. K., \& Elimam, H. (2017). Comparative effect of stevia rebaudiana and aspartame on hepato-renal function of diabetic rats: Biochemical and histological approaches. Journal of Applied Pharmaceutical Science, 7(8), 034-042.

Abhilash, M., Sauganthpaul, M. V., Varghese, M. V., \& Nair, R. H. (2011). Effect of long term intake of aspartame on antioxidant defense status in liver. Food and Chemical Toxicology, 49, 1203-1207.

Adaramoye, O. A., \& Akanni, O. O. (2016). Effects of long-term administration of aspartame on biochemical indices, lipid profile and redox status of cellular system of male rats. The Journal of Basic and Clinical Physiology and Pharmacology, 27(1), 29-37.

Al-Eisa, R. A., Hamza, R. Z., Mehana, A. E., \& El-Shenawy, N. S. (2018). The influence of L-carnitine on aspartame toxicity in kidney of male albino rats. International Journal of Pharmacology, 14, 1118-1127.

Ambaldhage, V. K., Naik, P. N., Alaparthi, R. K., \& Yalamanchi, S. (2016). Chemical of darkness (Melatonin): A ray of glow to dentistry. Journal of Indian Academy of Oral Medicine and Radiology, 28(2), 160-166.

Amin, A. H., El-Missry, M. A., \& Othman, A. I. (2015). Melatonin ameliorates metabolic risk factors, modulates apoptotic proteins and protects the rat heart against diabetes induced apoptosis. The European Journal of Pharmacology, 747, 166-173.

Ashok, I., \& Sheeladevi, R. (2015). oxidative stress evoked damage in rat hepatocytes leading to triggered nitric oxide synthase (NOS) levels on long term consumption of aspartame. JFDA, 23, 679-691.

Badary, O. A., Taha, R. A., Gamal El-Din, A. M., \& Abdel Whahab, M. H. (2003). Thymoquinone is a potent superoxide anion scavenger. Drug and Chemical Toxicology, 26, 87-98.

Bahr, H. I., \& Zaki, M. S. (2014). Renal genomic instability induced by aspartame and the possible influence of the flaxseed oil and coenzyme Q 10 in male rats. Life Sciences, 11(8), 301-308.

Banerjee, S. K., Maulik, M., Manchada, S. C., Dinda, A. K., Das, T. K., \& Maulik, S. K. (2001). Garlic-Induced alteration in rat liver and kidney morphology and Associated changes in endogenous antioxidant status. Food and Chemical Toxicology, 39, 793-797.

Bilton, R. (2013). Averting comfortable lifestyle crises. Science Progress, 96, 319-368.

Butchko, H. H., Stargel, W. W., Comer, C. P., Mayhew, D. A., Benninger, C., Blackburn, G. L., et al. (2002). Aspartame: Review of safety. Regulatory Toxicology and Pharmacology, 35(2), S1-S93.

CFR. (2005). CFR 21 Food and Drugs. Sec. 172.804 Aspartame. Food additives permitted for direct addition to food for human consumption.

Choudhary, A. K., \& Devi, R. S. (2014). Serum biochemical responses under oxidative stress in Wistar albino rats. Asian Pacific Journal of Tropical Disease, 4(1), 930-937.

Danaei, G. H., \& Karami, M. (2017). Protective effect of thymoquinone against diazinon-induced hematotoxicity, genotoxicity and immunotoxicity in rats. Environmental Toxicology and Pharmacology, 55, 217-222.

Doumas, B.T., \& Biggs, H.G. (1976). Standard method of clinical chemistry. Academic Press. Administration : 175.

ElHaliem, N. G., \& Mohamed, D. S. (2011). The effect of aspartame on the histological structure of the liver and renal cortex of albino rat and the possible protective effect of pimpinella anisum oil. Egyptian Jounal of Histology, 341, 715-725.

El-Sayed, M. F., Abdel-Kgaffar, SKh., Awaad, A., \& Mahmoud, M. M. (2019). Protective effects of melatonin and thymoquinone on hematological parameters, hepatic and renal enzyme activities against lithium-chloride toxicity in male albino rats. Journal of Pharmacological Chemistry, 5(1), 189-194.

Fernandez-Checa, J. C., Kaplowitz, N., Colell, A., \& Garcia, R. C. (1997). Oxidative stress and alcoholic liver disease. Alcohol Health and Research World, 21(4), 321-324.

Gomez- Moreno, G., Guardia, J., Ferrera, M. J., Cutando, A., \& Rieter, R. J. (2010). Melatonin in diseases of oral cavity. Oral Diseases, 16(3), 242-247.

Henry, R. J. (1964). Clinical chemistry, principles and techniques, p. 181.; Harper and ROW Publishers. 
Henry, R. J., Canone, D. C., \& Wink Elman, W. (1974). Clinical chemistry, principles and techniques. In 11 th Harper and ROW publishers, New York, p. 1629.

Hossienzadeh, H., Parvaedeh, H., Asi, M. N., Sadeghnia, H. R., \& Ziac, T. (2007). Effect of thymoquinone and Nigella sativa seeds oil on lipid peroxidation level during global cerebral ischemic/perfusion injury in rat hypo campus. Phytomedicine, 14, 621-627.

Hozayen, W. G., Soliman, H. A. E., \& Desouky, E. M. (2014). Potential protective effects of rosemary extract, against aspartame toxicity in male rats. Journal of International Academic Research for Multidisciplinary, 2(6), 110-125.

Hummadi, L. A. (2012). Histopathological and ultrastructure changes in renal corpuscle of female rats topical application by p- phenyl Diamine. International Journal of Zoological Research, 8, 106-120.

Hyvarinan, A., \& Nikkila, E. A. (1962). Determination of blood glucose with O.Tulodine. Nutrition Abstracts and Reviews, 32, 589.

Ibrahim, S. E., \& Hussien, T. D. (2014). Therapeutic influence of Allium cepa extract on aspartame induced oxidative stress and apoptotic changes in rat kidneys. AAMJ, 12(3), 182-212.

Kireev, R., Bitoun, S., Cuestar, S., Tejerina, A., Ibarrola, C., Moreno, E., Vara, E., \& Tresgueries, J. A. F. (2013). Melatonin treatment protects liver of Zucker rats After ischemic/reperfusion by diminishing oxidative stress and apoptosis. European Journal of Pharmacology, 701, 185-193.

Lebda, A. M., Tohamy, H. G., \& El-Sayed, Y. S. (2017). Long-term soft drink and aspartame intake induces hepatic damage via dysregulation of adipocytokines. And alteration of lipid profile and antioxidant status. Nutrition Research, 41, 47-55.

Maaruf, N. A., Mahmood, Z. M., \& Abdulhameed, T.T. (2017). Effect of aspartame on the liver of male albino rats: A histopathological and immuohistochemical study. Medical Journal of Babylon, 14(3), 558-566.

Magnuson, B. A., Burdock, G. A., Doull, J., Kroes, R. M., Moesh, G. M., Pariza, M. W., Spencer, P. S., Waddell, W. J., Walker, R., \& William, S. G. M. (2007), Aspartame, a safety elevation based on current use levels, regulations and toxilogical and epidemiological studies. Critical Review of Toxicology, 37, 629-727.

Marielza, R., Martins, I., \& Azoubel, R. (2007). Effects of aspartame on fetal kidney: A morphometric and stereological study. International Journal of Morphology, 25(4), 689-694.

Martins, M. R. I., \& Azoubel, A. R. (2007). Effects of aspartame on fetal kidney: A morphological and stereological study. International Journal of Morphology, 25, 689-694.

Mikaili, P., Maadirad, S., Moloudizargari, M., Aghajanshakeri, S., \& Sarahroodi, S. (2013). Therapeutic uses and pharmacological properties of garlic, shallot and their biologically active compounds. Iranian Journal of Basic Medical Sciences, 16, 1031-1048.

Moubarz, G., Waggas, A. M., Soliman, K. M., Abd Elfatah, A. Z., \&Taha, M. M. (2018). Effectiveness of aqueous extract of marjoram leaves in the treatment of aspartame liver toxicity. Egyptian Pharmaceutical Jounal, 17, $163-170$.

Nagi, M. N., Alam, K., Badary, D. A., Al-Sawaf, H. A., \& Al-Bekiary, A. M. (1999). thymoquinone protects carbon tetrachloridehepatotoxicity in mice via antioxidant mechanism. Biochemistry and Molecular Biology International, $47,153-159$.

Nasr, A. Y. (2014). Protective effect of aged garlic extract against the oxidative stress induced by Cisplatin on blood cell parameters and hepatic antioxidant enzymes in rats. Toxicological Report. 682-691.

Nasr, A. Y., \& Saleh, H. A. M. (2014). Aged garlic extract protects against oxidative stress and renal changes in Cisplatin — treated adult male rats. Cancer Cell International, 14(92), 1-12.
Nitescu, N. S. E., Ricksten, N., Marcussen, B., Haraldsson, U., Bilsson, S. B., \& Guron, G. (2006). N- Acetylcysteine attenuates kidney injury in rats subjected to renal ischemia-reperfusion. Nephrology, Dialysis, Transplantation, $21,1240-1247$.

Othman, A. I., Al Sharawy, S., \& El-Missiry, M. A. (2004). Role of melatonin in ameliorating lead induced haematotoxicity. Pharmacological Research, 50(3), 301-307.

Pagana, K. D., \& Pagana, T.J. (2002). Mosby's manual of diagnostic and Laboratory tests. 2nd ed. Mosby, p.1-44.

Parthasarathy, N. J., Kumar, R. S., Manikandan, S., \& Davi, R. S. (2006). oxidative stress in rat lymphoid organs. Journal of Occupational Health, 48, 20-27.

Patton, C. J., \& Crouch, S. R. (1977). Spectrophotometric and kinetics investigation of the Berthelot reaction for the determination of ammonia. Analytical Chemistry, 49, 464-469.

Principato, G. B., Aisa, M. C., Talesa, V., Rosi, G., \& Giovannini, E. (1985). Characterization of the soluble alkaline phosphatase from hepatopancreas of Squilla mantis L. Comparative Biochemistry and Physiology Part B: Comparative Biochemistry, 80(4), 801-804.

Prokic, M. D., Paunovic, M. G., Matic, M. M., Djordjevic, N. Z., Ognjanvic, B. I., Stajn, A. S., \& Saicic, Z. S. (2015). Effect of aspartame on biochemical and oxidative stress in rat blood. Archives of Biological Sciences, 67, 535-545.

Reitman, S., \& Frankle, S. (1957). Colorimetric method for aspartmte and alanine transaminases. American Clinical Pathology, pp. 28-56.

Rencuzoguilari, E., Tulu, B. A., Topaktas, M., Ila, H. B., Kayraldiz, A., Arslan, M., \& Diler, S. B. (2004). Genotoxicity of aspartame. Drug and Chemical Toxicology, 27(3), 257-268.

Rietz, B., Belagyi, J., Torok, B., \& Jacob, R. (1995). The radical scavenging ability of garlic examined in various models. Bulletin Chirico Farmaceutico, 13, 69-76.

Sajitha, G. R., Augusti, K. T., \& Jose, R. (2016). prophylactic effects of garlic oil and onion oil fractions as compared to vitamin $E$ on rats orally fed with lead acetate solution. Indian Journal of Clinical Biochemistry, 3(13), 260-264.

Shahdi-Pashaki, S., Teymourian, E., \& Tavakkoli-Moghaddam, R. (2018). New approach based on group technology for the consolidation problem in cloud computing-mathematical model and genetic algorithm. Computational and Applied Mathematics, 37(1), 693-718.

Shirzad, H., Taji, F., \& Rafieian-Kopaei, M. (2011). Correlation between antioxidant activity of garlic extract and wehi-164 fibrosarcoma tumor growth in BALB/C mice. Journal of Medicinal Food, 14, 969-974.

Soffritti, M., Belpoggi, F., Degli-Esposti, D., Lambeitini, L., Tibaldi, E., \& Rigano, A. (2006). First experimental demonstration of the malti potential carcinogenic effects of aspartame administered in the fed of Sprague-Dawley rats. Environmental Health Prespective, 114(3), 379-385.

Soffritti, M., Belpoggi, F., Tibldi, E., Esposti, D. D., \& Lauerioda, M. (2007). Lifespan exposure to low doses of aspartame beginning during prenatal life increases cancer effects in rats. Environmental Health Perspective, 115, 1293-1297.

Tsakirris, S., Giannoulia-Karantana, A., Simintgi, I., \& Schulpis, K. H. (2006). The effect of aspartame metabolites on human erythrocyte membrane acetyl cholinesterase activity. Phamacological Research, 53, 1-5.

\section{Publisher's Note}

Springer Nature remains neutral with regard to jurisdictional claims in published maps and institutional affiliations. 